\title{
Video Article Use of Capillary Electrophoresis Immunoassay to Search for Potential Biomarkers of Amyotrophic Lateral Sclerosis in Human Platelets
}

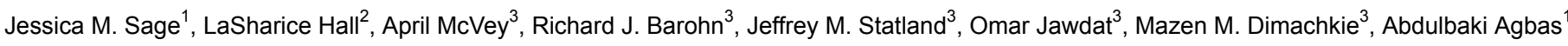 \\ ${ }^{1}$ Department of Basic Sciences, Kansas City University of Medicine and Biosciences \\ ${ }^{2}$ Rice University School of Medicine \\ ${ }^{3}$ University of Kansas Medical Center
}

Correspondence to: Abdulbaki Agbas at AAgbas@kcumb.edu

URL: https://www.jove.com/video/60638

DOI: doi:10.3791/60638

Keywords: Neuroscience, Issue 156, TDP-43, phosphorylated TDP-43, capillary electrophoresis, human platelet, neurodegenerative diseases, biomarker, predictive phosphorylation value, assay optimization

Date Published: 2/10/2020

Citation: Sage, J.M., Hall, L., McVey, A., Barohn, R.J., Statland, J.M., Jawdat, O., Dimachkie, M.M., Agbas, A. Use of Capillary Electrophoresis Immunoassay to Search for Potential Biomarkers of Amyotrophic Lateral Sclerosis in Human Platelets. J. Vis. Exp. (156), e60638, doi:10.3791/60638 (2020).

\section{Abstract}

Capillary electrophoresis immunoassay (CEI), also known as capillary western technology, is becoming a method of choice for screening disease relevant proteins and drugs in clinical trials. Reproducibility, sensitivity, small sample volume requirement, multiplexing antibodies for multiple protein labeling in the same sample, automated high-throughput ability to analyze up to 24 individual samples, and short time requirement make $\mathrm{CEI}$ advantageous over the classical western blot immunoassay. There are some limitations of this method, such as the inability to utilize a gradient gel $(4 \%-20 \%)$ matrix, high background with unrefined biological samples, and commercial unavailability of individual reagents. This paper describes an efficient method for running CEI in a multiple assay setting, optimizing protein concentration and primary antibody titration in one assay plate, and providing user-friendly templates for sample preparation. Also described are methods for measuring pan TDP-43 and phosphorylated TDP-43 derivative in platelet lysate cytosol as part of the initiative in blood-based biomarker development for neurodegenerative diseases.

\section{Video Link}

The video component of this article can be found at https://www.jove.com/video/60638/

\section{Introduction}

The overall goal of CEI as described here is to provide an updated stepwise protocol for analyzing target proteins in human platelets. Assignment of a blood-based signature molecule is one of the most important tasks in the field of biomarker development in human neurodegenerative diseases, such as Alzheimer's disease (AD), amyotrophic lateral sclerosis (ALS), frontotemporal lobar degeneration (FTLD), Parkinson's disease (PD), inclusion body myositis (IBM), and other protein-aggregation relevant pathologic conditions. The detection of minute amounts of such signature proteins in large volumes of blood with many interfering agents is a challenge. Therefore, the specificity, sensitivity, ability to handle large number of samples, and reproducibility of the selected method are crucial.

Human platelets can serve as a milieu to identify and assign potential biomarker proteins for neurodegenerative disease. Platelets provide the opportunity to serve as a surrogate primary cell model, which reflect some features of neuronal cells ${ }^{1,2,3}$. There are certain features that make platelets one of the preferred means to analyze biomarker candidate proteins and their chemical derivatives. First, platelets can be easily acquired using a less invasive approach by collecting blood from donors (i.e., venipuncture) or in large volumes from community blood banks. Second, platelets can be easily isolated from the whole blood with minimal preparatory work in minimally equipped laboratories ${ }^{4,5}$. Third, platelets do not have nuclei; therefore, they are a good model cell to study alterations in metabolism without transcriptional regulation. Fourth, the biomolecule content of platelets is encapsulated; therefore, the platelet microenvironment protects its contents from serum-interfering substances (i.e., proteases). Fifth, platelet-enriched plasma can be stored at room temperature for 7-8 days without losing metabolic activity. Therefore, platelets provide a working model in which external factors are minimized and controlled.

Traditional immunoassay techniques such as immunoblotting (e.g., western blotting) and enzyme-linked immunosorbent assay (ELISA) are more widely used in specific protein analysis. However, these two methods have several disadvantages, including multiple assay steps, requirement of hazardous chemicals and reagents, large sample size, issues with assay reproducibility, and inter-run data variabilities. These prompted the development of a method that is simpler with fewer steps and achievable in a relatively short period. Although the classical western blot technique will remain a popular laboratory method, its multi-step procedure, supplies, toxic waste (i.e., acrylamide, methanol, etc.) and assay time are becoming less desirable when performing high-throughput quantitative protein analysis.

An automated CEI approach is gradually becoming a method of choice for laboratories that conduct high-throughput protein assays ${ }^{6}$. CEI eliminates the need for gels, gel electrophoresis apparatuses, membranes, electrophoresis and electro-transfer devices, and more physical 
handling involvements. If designed well, a CEI assay should be completed within approximately $3.5 \mathrm{~h}$, including quantitative data analysis, publication quality electropherogram, and graphs with statistical analysis. Another superiority of the CEI system is its requirement of $10 x-20 x$ less protein concentration, making it ideal for use in human samples used in clinical trials ${ }^{7,8}$.

The most critical part of CEI is optimizing the assay conditions for each antibody purchased from different vendors, type of antibody (monoclonal vs. polyclonal), optimum protein concentrations, sample preparation, sample denaturation temperature, and electrophoresis voltage applied on the capillaries. We have developed a single-assay format optimization method for the CEI that should be implemented before any new assays, which will save time and resources. This optimization step is followed by an automated quantitative assessment of both total and phosphorylated derivative of transactivation response DNA/RNA binding protein (TARDP). Due to its size (43 kDa), the acronym TDP-43 will be used throughout this paper. Here, TDP-43 protein in human platelet lysate obtained from ALS patients are assessed to help develop predictive phosphorylation value (PPV) as a potential prognostic biomarker.

TDP-43 is a new potential disease biomarker candidate for ALS. TDP-43 is an omnipresent protein in all nucleated cells; therefore, the functions of TDP-43 during various normal cellular events and in neurodegenerative disease have been investigated ${ }^{9,10,11,12,13,14}$. Although TDP-43 is a nuclear protein ${ }^{15}$, it has the ability to shuttle in and out between the nucleus and cytoplasm due to the presence of nuclear localization and nuclear export sequences ${ }^{16,17,18,19}$. Cytoplasmic TDP-43 is involved in various cellular events, such as mRNA stability and transport, the stress response, mitochondrial function, autophagosome ${ }^{20}$. However, not much is known about the role of phosphorylated derivatives of TDP-43 other than their involvement in the pathogenesis of neurodegenerative disease ${ }^{21}$.

This protocol illustrates how to optimize the assay conditions to analyze the contents of TDP-43 and its phosphorylated derivative in platelets using the CEI approach. Since phosphorylated TDP-43 is not commercially available, it is proposed to use a predictive phosphorylation value (PPV) to assess TDP-43 profiles in ALS patients. This CEI system utilizes a small volume of sample mixture (2.5-3.0 $\mu \mathrm{L}$ per capillary). Total assay volume set-up is $8.0 \mu \mathrm{L}$ per capillary based on the manufacturer's protocol; hence, researchers can utilize one sample mixture preparation for two separate runs. The manufacturer designed the assay protocol so that any pipetting errors are minimized, if not entirely eliminated. The 24 individual human platelet lysate sample mixtures are divided into half-volumes (i.e., 2.5-3.0 $\mu \mathrm{L}$ per sample) and consecutively analyzed those by two different antibodies within $\sim 7 \mathrm{~h}$. The CEI system described here provides a desirable high-throughput assay modality. Users need to test antibodies from different vendors and sample preparation modalities for the target protein before performing large-scale screening.

\section{Protocol}

All protocols concerning the processing of human platelets follow the guidelines of both the University of Kansas Medical Center and Kansas City University of Medicine and Biosciences IRB committees.

\section{Preparation of buffers and reagents}

NOTE: Prepare all samples as per the manufacturer's guidelines. Wear personal protection equipment (lab coats, gloves, and goggles) during this procedure.

1. Prepare citrate wash buffer by combining $0.941 \mathrm{~g}$ of sucrose (11 mM final concentration), $6.4 \mathrm{~mL}$ of $5 \mathrm{M} \mathrm{NaCl}(128 \mathrm{mM}$ final), $5.4 \mathrm{~mL}$ of $0.2 \mathrm{M}$ $\mathrm{NaH}_{2} \mathrm{PO}_{4}$ (4.3 mM final), $9.4 \mathrm{~mL}$ of $0.2 \mathrm{M} \mathrm{Na}_{2} \mathrm{PHO}_{4}$ ( $7.5 \mathrm{mM}$ final), $0.352 \mathrm{~g}$ of sodium citrate (4.8 mM final), and $0.115 \mathrm{~g}$ of citric acid $(2.4 \mathrm{mM}$ final). Adjust the total volume to $250 \mathrm{~mL}$ with $\mathrm{ddH}_{2} \mathrm{O}$. Filter through a $0.45 \mu \mathrm{m}$ filter disk and adjust the pH to 6.5 . Store up to 1 year at $4{ }^{\circ} \mathrm{C}$. Bring the solution room temperature (RT) before use $\mathrm{e}^{22}$.

2. Prepare the rupture buffer by combining $250 \mathrm{mM}$ sucrose, $1 \mathrm{mM}$ EDTA, and $10 \mathrm{mM}$ Tris- $\mathrm{Cl}(\mathrm{pH} 7.4)$ in a $100 \mathrm{~mL}$ final volume. Store up to 1 year at $4{ }^{\circ} \mathrm{C}$. Add $2 \mu \mathrm{L}$ of phosphatase inhibitors cocktail (1:1000 final) and $1 \mu \mathrm{L}$ of protease inhibitors cocktail (1:2000 final) into $2 \mathrm{~mL}$ of rupture buffer. Keep on ice until use. Discard the unused rupture buffer.

\section{Platelet isolation}

1. Collect $8-10 \mathrm{~mL}$ of human blood in yellow-cap blood collection tube containing acid-citrate-dextrose (ACD) solution (75 mM trisodium citrate, $124 \mathrm{mM}$ dextrose, and $38 \mathrm{mM}$ citric acid, $\mathrm{pH}=7.4$; ACD:blood $=1: 9$ ). Gently mix the tube content $5 \mathrm{x}-6 \mathrm{x}$ inverting by hand.

2. Centrifuge the tubes at $200 \times g$ in a swinging bucket rotor for 20 min at RT.

3. Collect platelet-rich plasma (PRP) $(\sim 3-4 \mathrm{~mL})$ into a $15 \mathrm{~mL}$ conical bottom tube and leave approximately $0.5 \mathrm{~mL}$ of the PRP from the buffy coat (hazy-looking fraction) to avoid contamination. If any red blood cell contamination occurs, repeat this step.

4. Centrifuge the PRP samples at $1,200 \times g$ for $15 \mathrm{~min}$ at RT.

5. Wash the platelet pellets (P1) by gentle resuspension in $1 \mathrm{~mL}$ of citrate wash buffer and pellet by centrifugation at $1,200 \times g$ for $15 \mathrm{~min}$ at $\mathrm{RT}$.

6. Save the pure platelet pellet. Discard the supernatant.

7. Resuspend the platelet pellets in $600 \mu \mathrm{L}$ of the rupture buffer containing inhibitor cocktails.

8. Sonicate the platelet suspension using a sonicator. Place the sample in a mini ice bucket. Set the sonicator at setting 3 for $20 \mathrm{~s}$ in continuous mode.

NOTE: Make sure to clean the probe with $10 \%$ bleach followed by distilled water.

9. Centrifuge the sonicated samples at $20,000 \times g$ for $30 \mathrm{~min}$ at $4{ }^{\circ} \mathrm{C}$ to remove membranous fractions. Aliquot supernatants in $60 \mu \mathrm{L}$ and store at $-80^{\circ} \mathrm{C}$. Avoid repeated thawing/freezing cycles for the platelet cytosolic fractions.

\section{Preparation for CEI}

NOTE: $100 \mu \mathrm{L}$ of human platelet lysate was combined from ALS patients $(n=8-10)$, and healthy subjects $(n=8-10)$ were separately pooled and used for the assay optimization. 
1. Fill out in-house generated templates for the CEI layout (Table 1) and sample preparation (Table 2). The sample mixture preparation table is dynamic and will automatically calculate how much volume needs to be removed from source.

NOTE: When required source volume entered in dynamic Table-2, $0.1 \mathrm{X}$ sample buffer volume will be automatically calculated.

2. Pre-label $250.2 \mathrm{~mL}$ PCR tubes with capillaries \#1-\#25 and place them in a PCR rack. Set on ice.

3. Pre-label $0.6 \mathrm{~mL}$ microcentrifuge tubes: one for each primary antibody and dilution (if needed) to be used, one for the $0.1 \mathrm{x}$ sample buffer, one for the luminol-S/peroxide, and one for each sample to be diluted (if needed). Place them on ice in tube rack.

4. Take out the sample buffer, wash buffer, one plate, and a cartridge provided in the CEI separation 12-230 kDa master kit separation module.

5. From the $4{ }^{\circ} \mathrm{C}$ refrigerator, take out the antibody dilution buffer, primary antibodies, secondary antibodies, luminol, hydrogen peroxide, and standard pack. Place all reagents on ice, except the standard pack, which remains at RT.

NOTE: The reagents from the standard packs are lyophilized and sealed with a foil cover. These should be spun down briefly using a mini centrifuge before opening to reduce product loss. To open, the reagent tubes can either be pierced by a pipette tip or pulled back from the corner.

6. To prepare the $400 \mathrm{mM} \mathrm{DTT}$, add $40 \mu \mathrm{L}$ of deionized water to the clear tube containing the DTT.

7. To prepare $40 \mu \mathrm{L}$ of fluorescent $5 x$ master mix, add $20 \mu \mathrm{L}$ of the $10 x$ sample buffer and $20 \mu \mathrm{L}$ of the prepared $400 \mathrm{mM}$ DTT solution to the pink tube provided in kit.

8. To prepare the biotinylated ladder, add $16 \mu \mathrm{L}$ of deionized water, $2 \mu \mathrm{L}$ of $10 x$ sample buffer, and $2 \mu \mathrm{L}$ of the prepared $400 \mathrm{mM}$ DTT solution to the white tube provided in kit. Mix gently and transfer into a $0.2 \mathrm{~mL}$ PCR tube for denaturing.

9. Prepare $0.1 \mathrm{x}$ sample buffer by adding $1.5 \mu \mathrm{L}$ of $10 \mathrm{x}$ sample buffer and $148.5 \mu \mathrm{L}$ of deionized water to a $0.6 \mathrm{~mL}$ micro-centrifuge tube. Vortex to mix and place on ice.

10. Prepare the desired antibody dilutions. Add antibody diluent in volumes designated to each pre-labeled micro-centrifuge tube. If volumes are identical, use reverse pipetting technique ${ }^{23}$; if not, pre-rinse the pipette tip before dispensing.

NOTE: In this assay, a-TDP-43 pan antibody and a-p(S409/410-2) TDP-43 antibody were used. Anti-ERK antibody was used for an internal control to make sure that assay components are working.

11. Perform the reverse pipetting for antibody dilution as described below. Alternatively, additional information can be found in the literature ${ }^{24}$. NOTE: Reverse pipetting technique is preferred when dispensing small sequential volumes of solutions ${ }^{23}$. This technique offers some advantages: (i) providing a precise volume, (ii) eliminating the reagent foaming in the tip orifice, and (iii) ideal for small volume $(<5 \mu \mathrm{L}$ ) reagents, viscous solutions, surfactant solutions, and solutions with high vapor pressure.

1. Put a proper tip in a pipette and press the plunger down to the second stop (Step-2). Immerse the pipet tip a few millimeters into the solution. Slowly release the plunger to fill up the pipet tip with the solution while the tip is still immersed in the solution. Remove the tip from the solution and gently touch against the edge of the reagent reservoir so that excess liquid remaining on the outside of the tip is removed.

2. Dispense the solution by pressing the plunger down to first stop (Step-1). Do not dispense the remaining solution in the tip.

3. Empty the remaining solution in the tip to the reagent reservoir by pressing the plunger to the second stop (Step-2). Release the plunger to the ready position for the next pipetting step.

4. Add the required antibody in volumes designated to each pre-labeled microcentrifuge tube (Table 1) Do not pre-rinse the pipet tip: add it directly to the diluent and flush the tip multiple times to remove antibody. Place the tubes on ice.

12. To prepare the CEI sample-mix, perform the steps listed below for PCR tubes labeled cap\#2 through cap\#25: This is in the same order as it appears in Table 1.

1. Open all tubes, add $1.6 \mu \mathrm{L}$ aliquots of fluorescent $5 x$ sample buffer to each tube using a reverse pipetting technique, then close each PCR tube upon the addition of the $5 x$ buffer to minimize sample loss.

2. Open all tubes, add $0.1 \mathrm{x}$ sample buffer in volumes designated in Table 2 to each tube, then close immediately afterward. If volumes are identical, use a reverse pipetting technique. If not, pre-rinse pipet tip before dispensing $0.1 \mathrm{x}$ sample buffer.

3. Open all tubes, add protein sample in volumes designated in Table $\mathbf{2}$ to each tube, then close immediately afterward. If volumes are identical, use reverse pipetting technique. If not, pre-rinse pipet tip before dispensing $0.1 \mathrm{x}$ sample buffer.

4. Briefly centrifuge all PCR tubes in a benchtop centrifuge $(13,000 \times g$ for $30 \mathrm{~s})$, flick/vortex PCR tubes to mix, then repeat the centrifugation.

5. Transfer all PCR tubes into thermocycler with a heated lid. Denature samples at defined temperature and duration (i.e., $95{ }^{\circ} \mathrm{C}$ for 5 min; $70{ }^{\circ} \mathrm{C}$ for $10 \mathrm{~min}$ )

NOTE: The denaturation temperature and duration need to be optimized for target protein.

6. Repeat step 3.12.4.

7. Return all PCR tubes to tube rack and place on ice.

8. During the denaturing step, prepare the development solution (1:1 luminol-S:peroxide solution), then add $200 \mu \mathrm{L}$ of luminol-S and 200 $\mu \mathrm{L}$ of peroxide. Place on ice.

9. To load a CEI pre-filled plate with the sample prepared above, dispense reagents and samples into the assay plate shown in the assay layout (Figure 1). Avoid introducing air bubbles.

NOTE: If volumes and solution are identical, use a reverse pipetting technique. If not, pre-rinse the pipet tip before dispensing and do not expel the remainder into the plate well using the second tab stop on the pipette. A $12-230 \mathrm{kDa}$ separation module may contain a color-coded plate-loading guide. Place this guide under the plate while adding reagents and samples to the well, which visually helps when sample loading. The plate-loading guide can be downloaded from company website, as well.

1. In row $\mathrm{E}$, add $15 \mu \mathrm{L}$ of luminol:peroxide mix to each well.

NOTE: Ideally, prepare this reagent just before use and add to each well. If this is not convenient, this mixture may be prepared no more than 30 min prior to plate loading.

2. In row $\mathrm{D}$, to well $\mathrm{D} 1$, add $10 \mu \mathrm{L}$ of streptavidin-HRP.

3. In row $\mathrm{D}$, to wells $\mathrm{D} 2-\mathrm{D} 25$, add $10 \mu \mathrm{L}$ of designated secondary antibody.

4. In row $\mathrm{B}$, to each well, add $10 \mu \mathrm{L}$ of antibody diluent.

5. In row $\mathrm{C}$, to well $\mathrm{C} 1$, add $10 \mu \mathrm{L}$ of antibody diluent.

6. In row $\mathrm{C}$, to wells $\mathrm{C} 2-\mathrm{C} 25$, add $10 \mu \mathrm{L}$ of designated primary antibody.

7. In row $A$, to well $A 1$, add $5 \mu \mathrm{L}$ of biotinylated ladder from PCR tube \#1.

8. In row A, to wells A2-A25, add $3 \mu \mathrm{L}$ of the sample, PCR tubes \#2-\#25 into corresponding wells \#2-\#25. 
9. Add $500 \mu \mathrm{L}$ of wash buffer to each designated wash buffer well.

10. Centrifuge the plate for $5 \mathrm{~min}$ at $1,000 \times g$ at RT.

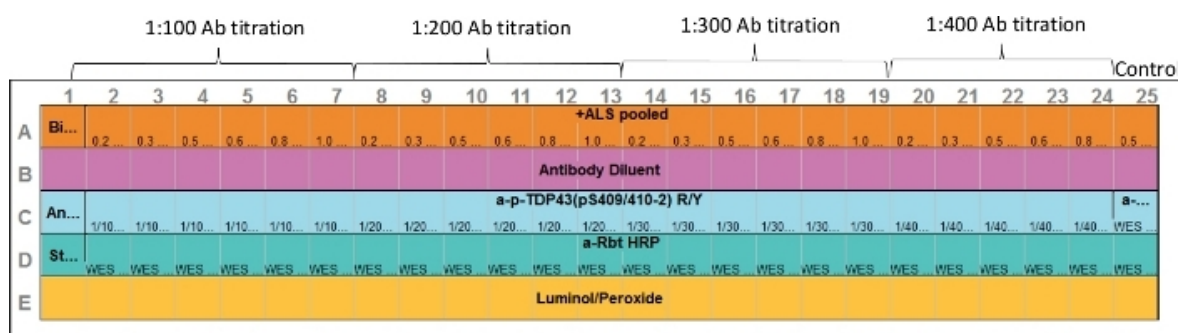

Figure 1: Assay layout. Both primary antibody and target protein sample optimization can be performed in one assay. Capillaries 2-7, 8$13,14-19$, and 20-24 represent various protein concentration and primary antibody range. Capillary 25 represents positive control. Anti-ERK antibody was used; however, any appropriate positive control can be included. Please click here to view a larger version of this figure.

\section{Performing the CEI on plate 1}

1. First, turn on the CEI (Table of Materials) analyzer, then turn on the computer. Open the software (Table of Materials)

2. Connect the analyzer to the online system (Table of Materials). This is a necessary step to collect the run data for trouble shooting purposes and data recovery.

3. Click on Instrument from the top-left menu, then click Connect. Select the instrument serial number which appears as a pop-up menu. Click Connect.

4. Select the "Assay" tab and select New Assay or select a saved template.

5. Input assay parameters (Table 1) or modify template currently. Save the file name and location.

6. Make sure that the blinking blue color indicator in the analyzer remains solid blue.

7. Touch the silver metal button on top of the orange door to open.

8. Carefully remove the capillary cartridge from its packaging. Insert the capillary cartridge as described by manufacturer's protocol. If correctly installed, the inside light turns to "blue".

9. Remove the protective seal from the assay plate. Visually observe the pre-filled wells for air bubbles. If observed, pop them with a small pipet tip (Long-shaft P10 pipet tip works well).

10. Load the plate holder by placing the assay plate and close the door. In computer, click on Start button.

1. Place ice tray containing temperature sensitive reagents and samples in the dark at $4{ }^{\circ} \mathrm{C}$ until ready to prepare second pre-filled plate.

2. Leave reagents/supplies out at room temperature for the second plate.

\section{Performing the CEI on plate 2}

NOTE: This plate is set for analyzing phosphorylated TDP-43 levels.

1. Remove the ice tray being stored at $4{ }^{\circ} \mathrm{C}$ and place it on the bench, $1 \mathrm{~h}$ before the estimated completion time of the first plate. Retrieve a second plate and cartridge.

2. Prepare any antibody dilutions needed for the second run and store them on ice. Prepare fresh 1:1 luminol-S:peroxide solution (step 3.12 .8 above).

3. Remix and briefly re-centrifuge the sample mix and reagents needed for loading the pre-filled plate. Load the second plate according to Figure 1. Load a-p(S409-410-2) TDP-43 antibody solution in row C wells.

4. When the first run is complete, discard the first plate and cartridge. Remove the cartridge and place in a sharp's container for disposal. Keep the stickers from the plate and cartridge for reference purposes.

5. Close the software file and reselect the same template. The software will remember the settings from the prior run. Make any changes to the annotation as needed (i.e., changing the primary antibody).

6. Repeat steps 4.8-4.10. Put away all 12-230 kDa master kit separation module reagents and supplies

7. Discard left over CEI sample-mix, antibody dilutions, $0.1 x$ sample buffer and luminol-S:peroxide mixes in accordance with university regulations.

\section{Data analysis}

1. Once the run is completed, ensure that the following quality checks are performed.

1. In software, select the Show Standards icon and Graph View tab. Check all 25 capillaries for the peak alignments to internal fluorescent marker sizes. Correct the misalignments by selecting Force Standard or right-clicking on the incorrect peak then selecting Not a Standard. Perform this check for each new capillary.

2. Click on Samples and the Single View icon. Select capillary \#1 (biotinylated ladder) in the experiment tab. Review the peak alignments to molecular weight markers. Click on the peak in Graph View and select Remove Peak, if an incorrect selection of the peak is done by the software.

NOTE: As an example, the 12-230 KDa biotinylated ladder will show sizing peaks at $12 \mathrm{kDa}, 40 \mathrm{kDa}, 66 \mathrm{kDa}, 116 \mathrm{kDa}, 180 \mathrm{kDa}$, and $230 \mathrm{kDa}$. The sizing of the sample peaks will be incorrect if this step is not performed and will generating inaccurate results. 
3. View the electrophoretic movie and note if any abnormal migration occurred during the run.

4. Derive data (e.g., peaks table, including molecular weight, peak area, peak height, and signal-to-noise [S/N]) as needed for further calculations. There are graph annotation tools located at the upper-right corner of Graph window for providing more information about the graph.

\section{Representative Results}

Optimization of platelet cytosolic protein concentration and primary antibody titration

It is important to establish a linear dynamic range of platelet cytosolic proteins in the assay, since changes in signal are directly proportional to changes in protein in the platelet cytosol. Use of whole platelet lysate mixture in the assay may reduce the signal intensity of the target proteins (TDP-43 and P(S409-412) TDP-43) and contribute to a high background signal. Therefore, in this assay, the clear supernatant was used (cytosolic fraction) after rupturing platelets (Figure 2).

A

Whole platelet homogenate

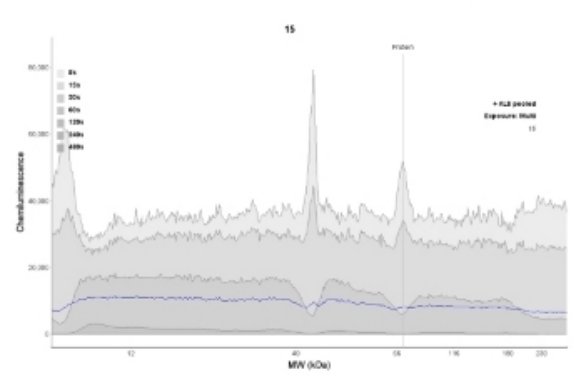

B

\section{Platelet cytosolic fraction}

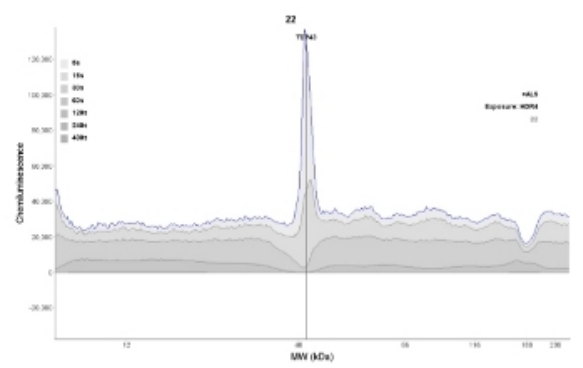

Figure 2: Signal clarity depends on the sample quality. (A) Whole platelet lysate homogenate interferes with anti-TDP-43 antibody binding; therefore, a noisy electropherogram was observed. (B) Platelet cytosolic fraction was obtained from subjecting the whole lysate to centrifugation $(16,000 \times \mathrm{g}$ for $30 \mathrm{~min})$. Most of the membranous proteins were removed; hence, anti-TDP-43 antibody binding to TDP-43 protein was enhanced (blue line trace). Please click here to view a larger version of this figure.

A linear dynamic range for platelet cytosol protein concentration was established at $0.2-0.8 \mathrm{mg} / \mathrm{mL}$. An assay template was adopted so that both protein concentration and primary antibody titration were able to be performed in one assay (Figure 3 ).

A

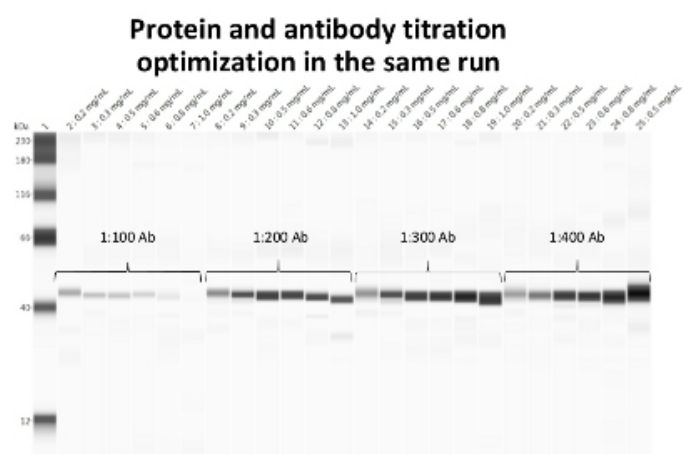

B

Determining the linear dynamic range

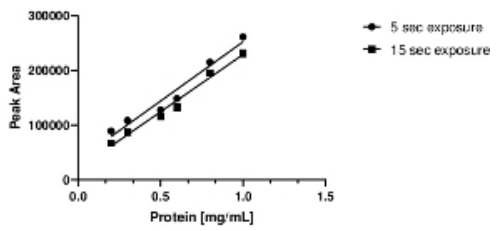

Figure 3: Linear dynamic range for platelet cytosol protein concentration. (A) Both protein concentrations and antibody titrations were optimized in one plate during the same run. (B) The linear working range $(0.2-0.8 \mathrm{mg} / \mathrm{mL}$ ) for protein was established. A $0.5 \mathrm{mg} / \mathrm{mL} \mathrm{protein}$ load was labeled by a-ERK antibody as the positive control (capillary 25). Please click here to view a larger version of this figure.

It should be noted that glycerol content in the sample preparation tube should be less than $20 \%$ (final), otherwise the high glycerol concentration will adversely affect the primary antibody binding.

\section{Determining optimum exposure time}

In the older version of the software, the optimum exposure time had to be determined by plotting peak area against protein concentration (mg/ $\mathrm{mL}$ ). The new version provides a new tool named the high dynamic range (HDR) detection profile (Figure 4). Using the image panel provided the option to view all exposure times (i.e., $5 \mathrm{~s}, 15 \mathrm{~s}, 30 \mathrm{~s}, 60 \mathrm{~s}, 120 \mathrm{~s}, 240 \mathrm{~s}, 480 \mathrm{~s}$ ) together. Computer software analyzed all exposure times and automatically identified the best exposure time (HDR). HDR detection profile delivered a significantly wider dynamic range due to the greater sensitivity of $\mathrm{CEI}$, which means better detection and quantitation over a larger sample concentration range. However, users still have the option to choose any exposure time that satisfies the experimental goal. Using this feature, optimum exposure time was found for TDP-43 protein. The peak represents the optimum exposure time (Figure 4A). A single exposure time (4 s) was defined for this antibody after reviewing all nine exposure times ranging between 1-512 s (Figure 4B). 
A

High Dynamic Range (HDR)

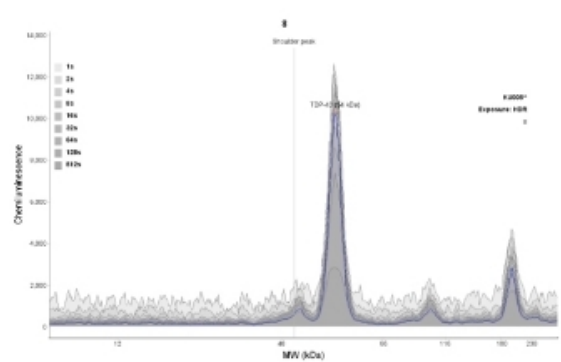

B

Single exposure time

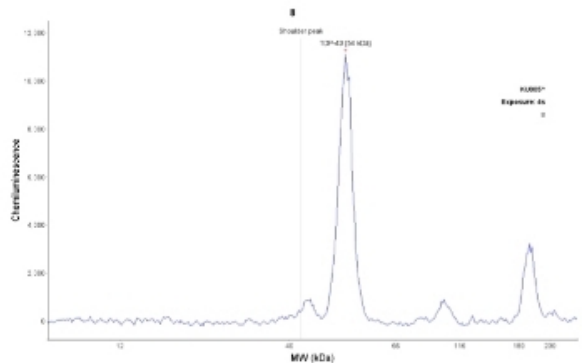

Figure 4: High dynamic range (HDR) detection profile for a target protein. (A) TDP-43 protein peak represents the optimum exposure time for the target protein. a-TDP-43 Ab titration was 1:300, and platelet cytosol protein concentration was $0.5 \mathrm{mg} / \mathrm{mL}$. The software-defined blue line indicates the optimum exposure time. (B) This figure represents a user-defined single exposure time (4 s) after reviewing all nine exposure times ranging between 1-512 s. Please click here to view a larger version of this figure.

\section{TDP-43 levels in human platelet cytosol of ALS patients}

A blood base biomarker development was performed. Using optimized assay conditions, platelet lysate cytosolic fractions obtained from ALS patients were analyzed using two sets of antibodies (i.e., anti-TDP-43 [Pan] antibody, an antibody that recognizes phosphorylated derivatives of TDP-43 protein; here, a-P [S409/410-2] TDP-43 was used). In this demonstration, disease-specific TDP-43 and its phosphorylated derivative are presented (Figure 5).

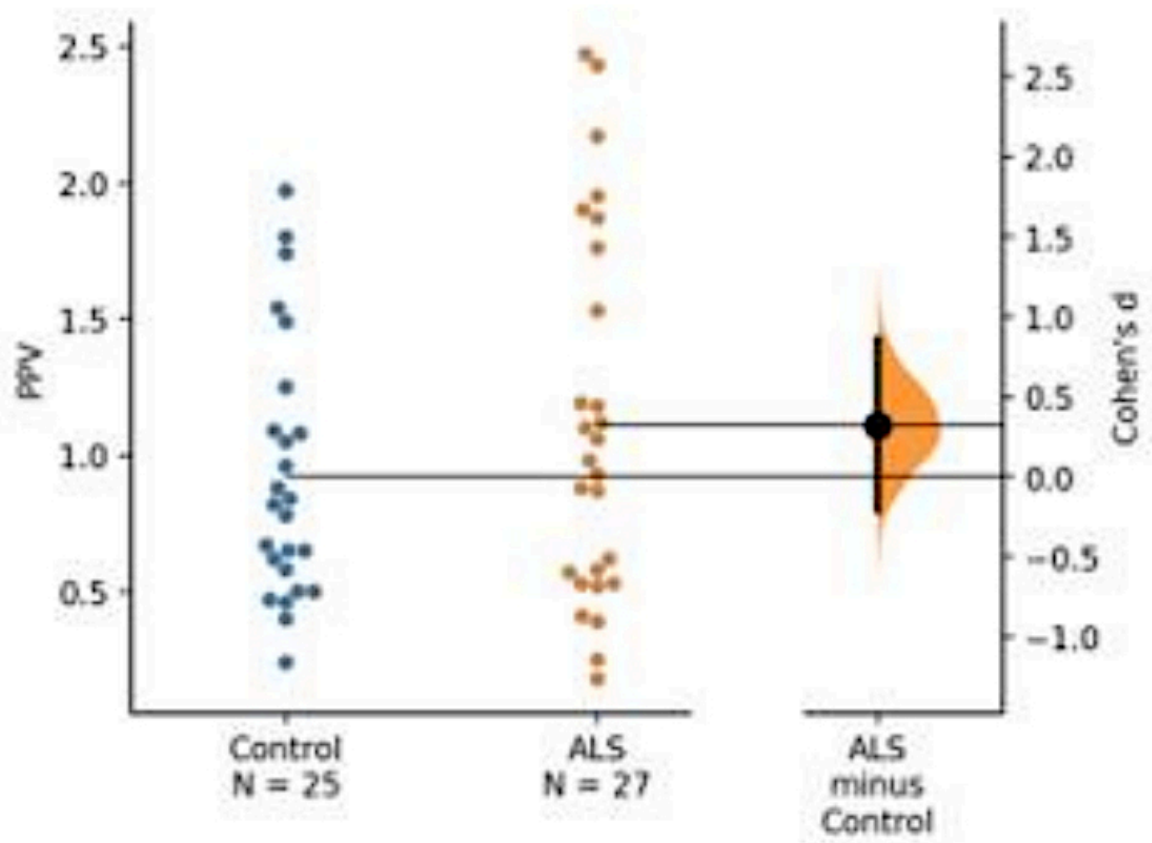

Figure 5: A representation of predictive phosphorylation value (PPV) of TDP-43. Absolute amount of phosphorylated TDP-43 and pan TDP-43 alone did not show much difference between the ALS and control groups. However, PPV indicated a slight increase in the ALS cohort, although there was no statistical difference between the two groups due to insufficient numbers of subjects $(A L S=25$, control $=27)$. A low Cohen's d value between the means of ALS and control group showed a low effect size between the two groups due to small sample size (control $=25, A L S=27)$. Please click here to view a larger version of this figure.

Total TDP-43 was quantified using the calibration curve (Figure 6) 


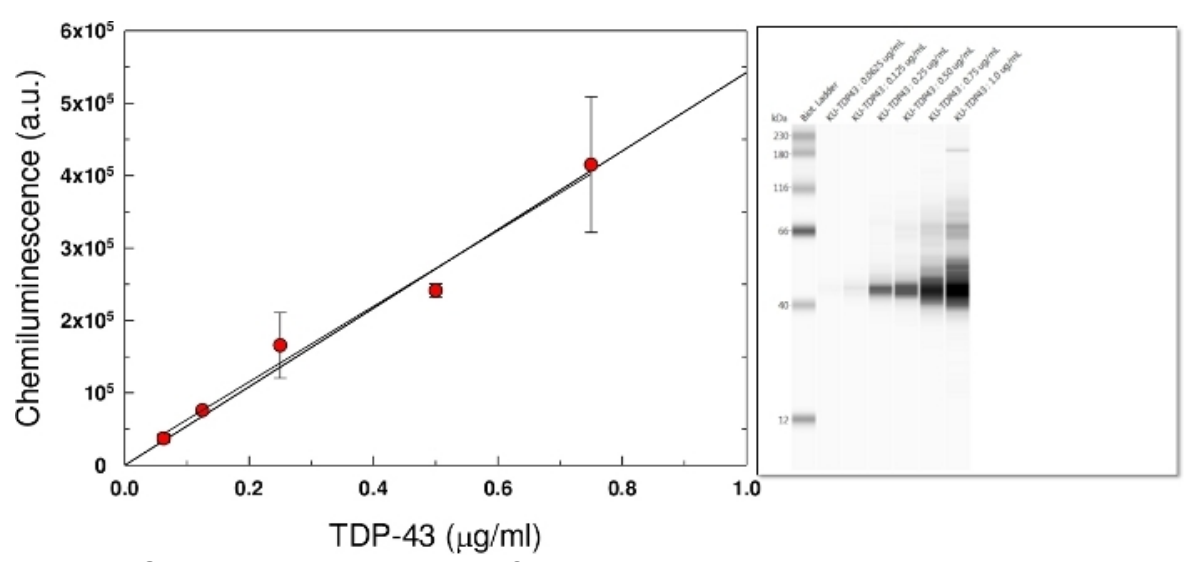

Figure 6: Standard calibration curve. Commercially purchased recombinant TDP-43 protein concentrations were used to construct a standard curve. Each data represents the average of triplicates. The protein band intensities were concentration dependent (Inset). Please click here to view a larger version of this figure.

The quantification of phosphorylated TDP-43 protein was not possible due to commercially unavailability of this protein. Instead, a predicted phosphorylation value (PPV) was established that defines the percent of the phosphorylated species of TDP-43. PPV was determined from two sequential $\mathrm{CEI}$ assays for the same sample using the following equation.

$\mathrm{PPV}=($ Fluorescence a.u. $p(S 409-410-2) T D P-43)$

$\div$ (Fluorescence a.u. pan TDP - 43)

Intra- and inter-run assay variability were tested in pooled human ALS platelet cytosolic fractions (Figure 7)

A

Intra-run assay variation

\section{B}

Inter-run assay variation

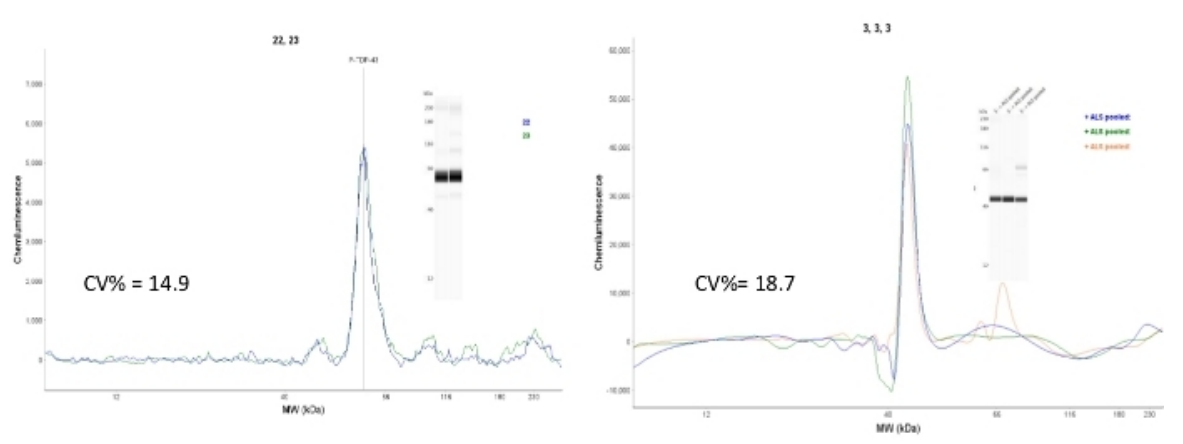

Figure 7: Assay variations. (A) Two capillaries loaded with the same sample were analyzed by CEI, and intra-run assay variation was calculated as $\mathrm{CV} \%=14.9$. (B) The same sample was analyzed on three different assay days and in three different assay runs. Inter-run assay variation was calculated as $\mathrm{CV} \%=18.7$. Please click here to view a larger version of this figure.

Although intra-run (capillary-to-capillary variation) coefficient variation values fell in the acceptable range (CV\% $=14.9)$, the inter-run assay value was relatively high $(\mathrm{CV} \%=18.7)$. It is interpreted that this variation may be due to using capillary cartridges and sample plates from different lots. It is recommended that reproducibility studies should be performed in CEI components that have the same lot number.

Table 1: CEI assay plate loading template. Please click here to download this table.

Table 2: Interactive sample mixture preparation template. After entering the stock protein concentration from unknown samples, interactive cells will automatically calculate how much volume needs to be used for preparing the sample mix. Please click here to download this table.

\section{Discussion}

The capillary electrophoretic-based immunoassay is now the method of choice for high-throughput sample analysis and drug screenings ${ }^{25}$. Small sample volumes, well-optimized assay components, user-friendly assay platform and instrumentation, reagent expenditure, and low CV percentage are primary advantages ${ }^{26,27}$. Although there are several methods for separating proteins in different assay modalities, the antibodybased CEI described here can be adapted by small laboratories that are engaged in blood-based biomarker development. The CEI assay technology used here provides reliable, reproducible, and sensitive measurements for TDP- $43^{28}$ and its phosphorylated derivative ${ }^{5}$.

The CEI system also provides a multiplexing choice of analyzing TDP-43 and its phosphorylated derivatives simultaneously and providing the direct quantification of the target protein, if purified or recombinant target protein is available. Full-length recombinant TDP-43 protein is commercially available; however, recombinant phosphorylated TDP-43 derivative is not. Since phosphorylated TDP-43 is not commercially 
available, a predictive phosphorylation value (PPV) was implemented to assess TDP-43 profile in ALS patients. Pan TDP-43 and phosphorylated TDP-43 amounts were permanently labelled with a fluorophore; therefore, the TDP-43 profile remains the same with or without a quantitative unit (i.e., $\mathrm{ng} / \mathrm{mL}, \mathrm{pg} / \mathrm{mL}$, etc.). Although determining the absolute amount of TDP-43 and its phosphorylated derivatives (i.e., P [S409-410-12] TDP-43) provides a more quantitative measurement, calculating PPV eliminates the necessity of the recombinant phosphorylated TDP-43 for standardization, since it is not commercially available.

CEI provides several checkpoints in the assay platform to accurately identify the problem in the case that an assay fails. This eliminates obstacles and provides better experimental design. The assay procedure is fully automated except for filling the sample plate. This is a significant feature compared to standard western blotting analysis. This feature provides consistency from run-to-run. Although every laboratory has unique standard operating procedures, it is important to adhere to practices that minimize human error. For example, it is critical to prepare the luminol-S/peroxide mixture just before plate loading, since adding peroxide into luminol starts the enzymatic reaction and consumes the luminol substrate. Loading samples and primary/secondary antibodies into plate wells without air bubbles are also critically important steps.

Additionally, since the plate wells are small in volume and there is no space between wells, users should use caution while pipetting, which is the most important step since everything else is automated. The loading order of the samples, antibodies, and other reagents is important for consistency of the assay (Figure 1). The process of plate preparation takes about $40-45 \mathrm{~min}$. Therefore, it is recommended to first load the plate with the required assay components and prepare the luminol-S/peroxide mixture just before pipetting. This way, there is a consistent sequence of reagent adding, and consistent luminescence signal strength will be attained. It is not recommended to use an expired luminolS/peroxide reagent, as it primarily affects the strength of the peroxide. Recent progress in introducing the split-buffer system and including the chemical and detergent compatibility range has enhanced the assay quality and produced more reproducible and predictable results. Now, a new combo-analyzer from the same manufacturer possesses a feature for analyzing the samples labeled with chemiluminescence and fluorescence conjugated antibodies in the same run. This new feature eliminates the need to consecutively run two individual plates and eliminates run-to-run variation.

The assay plates should be stored in ambient temperature. If it is chosen to keep the assay plates in a $4{ }^{\circ} \mathrm{C}$ refrigerator, the plates must be taken out the night before the assay and brought to ambient temperature. Incorrectly loaded sample wells need to be extensively (4-5 times) washed with buffer provided in kit before adding the correct sample. Each primary antibody and biological samples are unique; therefore, the antibody/ protein optimization should be performed before analyzing the samples for target proteins in biological fluids.

Here, the primary antibody incubation time was set for $30 \mathrm{~min}$ by default. If the signal is weak, users should consider increasing the primary antibody incubation time until reaching the desired signal strength without fluorescence signal burnout. For human platelets, pooled samples from patients were prepared and used for an optimization assay. The sample pooling better represents the variation among target biomolecules. It is recommended to use clear supernatants rather than total lysate or total homogenate for the CEI.

The high concentration of protein in whole platelet lysate mixture may decrease the signal-to-noise ratio (Figure 2). Repeated freeze-thaw cycles of samples should be avoided, as this adversely affects primary antibody binding. The ingredients of the lysate buffer are important, as some reagents are not compatible with $\mathrm{CEI}^{29}$. It is advised to cross-check the list of compatible reagents provided on the manufacturer's website before sample preparation. This is a limitation of the system that does not tolerate high stringency conditions for sample preparation. It is recommended to optimize the assay run parameters (i.e., primary antibody dilution, protein concentration, primary antibody incubation time, etc.) using pooled samples to subsequently analyze the individual samples.

\section{Disclosures}

The authors declare no competing financial interest except ProteinSimple, Inc. covered the publication cost of this manuscript.

\section{Acknowledgments}

This research was sponsored by an intramural grant awarded for A.A. This work was supported by a CTSA grant from NCATS awarded to the University of Kansas Medical Center for Frontiers: The Heartland Institute for Clinical and Translational Research (\#UL1TR606381). The contents are solely the responsibility of the authors and do not necessarily represent the official views of the NIH or NCATS. We are thankful for The University of Kansas Medical Center ALS clinic personal for obtaining IRB approval for blood sample collection from healthy volunteer and ALS patients. The authors thank Emre Agbas for proofreading of the manuscript.

\section{References}

1. Blair, P., Flaumenhaft, R. Platelet alpha-granules: basic biology and clinical correlates. Blood Reviews. 23 (4), 177-89 (2009).

2. Mercado, C. P., Kilic, F. Molecular mechanisms of SERT in platelets: regulation of plasma serotonin levels. Molecular Interventions. 10 (4), 231-41 (2010).

3. Goubau, C. et al. Regulated granule trafficking in platelets and neurons: a common molecular machinery. European Journal of Paediatric Neurology. 17 (2), 117-25 (2013).

4. Basu, S. S. et al. Human platelets as a platform to monitor metabolic biomarkers using stable isotopes and LC-MS. Bioanalysis. $\mathbf{5}$ (24), 3009-21 (2013).

5. Wilhite, R. et al. Platelet phosphorylated TDP-43: an exploratory study for a peripheral surrogate biomarker development for Alzheimer's disease. Future Science OA. 3 (4), FSO238 (2017).

6. Worth, A. J. et al. LC-MS Analysis of Human Platelets as a Platform for Studying Mitochondrial Metabolism. Journal of Visualized Experiments. (110), e53941 (2016).

7. Statland, J. M. et al. Rasagiline for amyotrophic lateral sclerosis: A randomized, controlled trial. Muscle and Nerve. 59 (2), $201-207$ (2019) 
8. Charytan, D. M. et al. Safety and cardiovascular efficacy of spironolactone in dialysis-dependent ESRD (SPin-D): a randomized, placebocontrolled, multiple dosage trial. Kidney International. 95 (4), 973-982 (2019).

9. Ugras, S. E., Shorter, J. RNA-Binding Proteins in Amyotrophic Lateral Sclerosis and Neurodegeneration. Neurology Research International. 432780 (2012).

10. Amador-Ortiz, C. et al., TDP-43 immunoreactivity in hippocampal sclerosis and Alzheimer's disease. Annal of Neurology. 61 (5), $435-45$ (2007).

11. Baloh, R. H. TDP-43: the relationship between protein aggregation and neurodegeneration in amyotrophic lateral sclerosis and frontotemporal lobar degeneration. FEBS Journal. 278 (19), 3539-49 (2011).

12. Buratti, E., Baralle F. E. The molecular links between TDP-43 dysfunction and neurodegeneration. Advances in Genetics. 66, 1-34 (2009).

13. Guo, W. et al. An ALS-associated mutation affecting TDP-43 enhances protein aggregation, fibril formation and neurotoxicity. Nature Structural Molecular Biology. 18 (7), 822-30 (2011).

14. Geser, F. et al. Motor neuron disease clinically limited to the lower motor neuron is a diffuse TDP-43 proteinopathy. Acta Neuropathologica. 121 (4), 509-17 (2011).

15. Neumann, M. et al. Ubiquitinated TDP-43 in frontotemporal lobar degeneration and amyotrophic lateral sclerosis. Science. 314 (5796), 130-3 (2006).

16. Buratti, E., Baralle F. E. TDP-43: gumming up neurons through protein-protein and protein-RNA interactions. Trends in Biochemical Sciences. 37 (6), 237-47 (2012).

17. Fallini, C., Bassell, G. J., Rossoll, W. The ALS disease protein TDP-43 is actively transported in motor neuron axons and regulates axon outgrowth. Human Molecular Genetics. 21 (16), 3703-18 (2012).

18. Ayala, Y. M. et al. Structural determinants of the cellular localization and shuttling of TDP-43. Journal of Cell Sciences. 121 (Pt 22), $3778-85$ (2008).

19. Fiesel, F. C., Kahle, P. J. TDP-43 and FUS/TLS: cellular functions and implications for neurodegeneration. FEBS Journal. 278 (19), $3550-68$ (2011).

20. Birsa, N., Bentham, M. P., Fratta, P. Cytoplasmic functions of TDP-43 and FUS and their role in ALS. Seminars in Cell and Development Biology. pii: S1084-9521(18)30197-6 (2019).

21. Liachko, N. F. et al. CDC7 inhibition blocks pathological TDP-43 phosphorylation and neurodegeneration. Annals of Neurology. 74 (1), $39-52$ (2013).

22. Qureshi, A. H. et al. Proteomic and phospho-proteomic profile of human platelets in basal, resting state: insights into integrin signaling. PLoS One. 4 (10), e7627 (2009).

23. Suominen, I., Koivisto, S. Increasing Precision When Pipetting Protein Samples: Assessing Reliability of the Reverse Pipetting Technique. American Laboratory. (2011).

24. Pipetting tool box for life sciences. https://www.mt.com/us/en/home/library/guides/laboratory-division/life-science/pipetting-toolbox-for-lifesciences.html (2019).

25. Hale, L. J. et al. 3D organoid-derived human glomeruli for personalised podocyte disease modelling and drug screening. Nature Communication. 9 (1), 5167 (2018).

26. Chen, J. Q., Wakefield, L. M., Goldstein, D. J. Capillary nano-immunoassays: advancing quantitative proteomics analysis, biomarker assessment, and molecular diagnostics. Journal of Translational Medicine. 13, 182 (2015).

27. Moser, A. C., Hage, D. S. Capillary electrophoresis-based immunoassays: principles and quantitative applications. Electrophoresis. 29 (16), 3279-95 (2008).

28. Fourier, A. et al. Development of an automated capillary nano-immunoassay-Simple Western assay-to quantify total TDP43 protein in human platelet samples. Analytical and Bioanalytical Chemistry. 411 (1), 267-275 (2019).

29. Compatibility, S.W.S.A.B. https://www.proteinsimple.com/technical_library.html (2017). 